\title{
Periodismo y propaganda en el Perú. Una relación compleja durante los procesos electorales
}

\author{
Recibido: 14 de agosto de 2013 \\ Aceptado: 26 de marzo de 2014 \\ Publicado: 28 de noviembre de 2014
}

\author{
Ghiovani Hinojosa Navarro \\ ghinojosa19@gmail.com
}

Universidad de San Martín de Porres (Perú)

\begin{abstract}
Resumen: El 10 de abril de 2016 serán las elecciones presidenciales en el Perú. Los medios de comunicación cubrirán las actividades de los principales candidatos y hurgarán en sus hojas de vida. En este proceso, la prensa estará tentada a usar técnicas propias de la propaganda, una categoría asociada tradicionalmente a los actores políticos. Por ejemplo, podrá apelar a estereotipos, expresar su opinión a través de fuentes aparentemente independientes y seleccionar hechos para construir un discurso ideológico. Por su lado, los agentes de prensa de los candidatos y los expertos en marketing político estarán a la caza de los periodistas.
\end{abstract}

Palabras clave: Periodismo, propaganda, marketing político, elecciones, persuasión.

Abstract: 10 April 2016 will be the presidential election in Peru. The media will cover the activities of the leading candidates and rummage in their resumes. In this process, the press will be tempted to use propaganda techniques, a category traditionally associated with political actors. For example, they may appeal to stereotypes, express their opinion through seemingly independent sources and select facts to build an ideological discourse. For its part the press agents of candidates and political marketing experts are hunting for journalists.

Key words: Journalism, Propaganda, Political Marketing, Elections, Persuasion.

\section{Introducción}

La propaganda es un concepto propio de los actores políticos, que se valen de ella sobre todo en tiempos electorales. En este artículo, se entiende por propaganda el cúmulo de discursos, spots televisivos, afiches, entre otros mensajes, que los candidatos dirigen a sus 
potenciales electores. Los medios de comunicación son, en teoría, entidades independientes que procesan la información oficial de los aspirantes a gobernantes y le dan un tratamiento propio. Así, los periodistas están llamados a cotejar la idoneidad de los candidatos y a poner a prueba la consistencia de sus planes. En suma, propaganda y periodismo pueden ser vistos como actividades contrapuestas.

Sin embargo, en sociedades como la peruana, existen indicios de un uso soterrado de técnicas de propaganda por parte de los medios de comunicación. Diarios, canales de televisión y estaciones de radio se ven tentados con frecuencia a recurrir a estos recursos persuasivos. Un sector de la prensa acorta la distancia que tiene con los actores políticos y se convierte en casi un participante activo de la contienda.

Los estudios habitualmente abordan la propaganda política y el periodismo de forma diferenciada, por lo que el presente artículo se propone vincularlos. Esta aproximación puede servir como punto de partida para analizar las elecciones generales del 10 de abril de 2016.

\section{Persuasión y propaganda}

Lo primero, antes de analizar el periodismo, es diferenciar la persuasión de la propaganda. Hay dos tendencias cuando se trata de definir la persuasión. La primera la ve como un proceso racional y demostrativo, mientras que la segunda la entiende como un proceso, además racional y demostrativo, profundamente emotivo. En la primera postura están teóricos como Roiz (1994: 6), quien asegura que persuadir es "convencer a alguien con razones y argumentos para que crea algo (afectando al nivel psicológico-social de las actitudes y valores) o realice una acción (compre, vote, asista a un mitin o modifique sus conductas sobre algún aspecto de la realidad: producto comercial, ideas políticas o religiosas)".

Reardon (1991: 31) también tiene una concepción "racionalista" de la persuasión. Para ella este proceso no es otra cosa que "la actividad de demostrar y de intentar modificar la conducta de por lo menos una persona mediante la interacción simbólica. Es una actividad consciente y se produce: $a$ ) cuando se registra una amenaza contra el objetivo de una persona; y $b$ ) cuando la fuente y el grado de esta amenaza son suficientemente importantes como para justificar el coste del esfuerzo que entraña la persuasión". Así, Reardon introduce un elemento nuevo en la definición: la idea de que la persuasión puede ser una forma de defenderse de la potencial agresión del otro.

Tanto Roiz como Reardon analizan la persuasión desde un punto neutral, es decir la usan indistintamente para referirse a la manipulación de masas o a la educación escolar, por ejemplo. Roiz (1994: 23), avanzando en su teoría, distingue tres tipos de persuasión: la "cognoscitiva", que está presente en el periodismo; la "ideológica", que está en la propaganda, ya sea política o religiosa; y la "comercial", que es llevada a cabo por la publicidad. La segunda tendencia en torno a la persuasión destaca el uso que hace el persuasor de los recursos emocionales. Por ejemplo, Jordi Berrio explica lo siguiente: 
"El orador, además de argumentos, muchas veces tendrá que dirigirse a la capacidad emotiva de su público. En la persuasión existen, pues, dos aspectos, uno racional y otro irracional, a diferencia de lo que pasa en el convencimiento, que es un fenómeno esencialmente racional. Persuadir es, por lo tanto, una operación más compleja en el aspecto psicológico, puesto que trabaja en una doble vía" (ápud Parra, 1989: 15).

Persuadir, así, aparece como una operación más racional que "manipular" pero menos racional que "convencer". Chaïm Perelman y Lucie Olbrechts-Tyteca consideran que "para quien le interesa el resultado, persuadir es más que convences, pues las convicciones no son sino el primer estadio que conduce hacia la acción [...] Contrariamente, para quien está preocupado por el carácter racional de la adhesión, convencer es más que persuadir" (ibídem: 14). En suma, la persuasión es aquella comunicación por la que el emisor busca influir en las creencias y conductas de alguien a través de recursos racionales y emotivos.

Como concepto, la propaganda tiene un problema parecido al de la persuasión: hay dos tendencias teóricas casi opuestas, una que la considera como algo neutral y hasta positivo, y otra que le da un sentido negativo. La primera tendencia hunde sus raíces en la misma etimología del término, según la cual propaganda viene del latín propagare, que significa "meter en la tierra los tallos" de una planta para multiplicarla. En el plano simbólico, sería promover la difusión de una idea. Tal fue el significado que le dio la Iglesia Católica a esta palabra cuando creó, en 1633, una oficina llamada Congregatio de Propaganda Fide ("Congregación de Propagación de la Fe"). Esta dependencia fue concebida para contrarrestar el avance del protestantismo.

Fue recién en el siglo XX que la palabra propaganda perdió su significado religioso. El Instituto para el Análisis de la Propaganda, nacido en Estados Unidos antes de la Segunda Guerra Mundial, la define como "la expresión de la opinión o la acción por parte de individuos o grupos designados deliberadamente con el fin de influir sobre opiniones o acciones de otros individuos o grupos" (ibidem: 22). En esa línea:

"Podemos definir la propaganda como el uso más o menos deliberado, planeado y sistemático de símbolos, principalmente mediante la sugestión y otras técnicas psicológicas, con el propósito, en primer lugar, de alterar y controlar las opiniones, ideas y valores, y en último término, de modificar la acción manifiesta, según ciertas líneas predeterminadas. La propaganda puede ser abierta y su propósito confesado, o bien puede ocultar sus intenciones. Se encuentra situada siempre dentro de un marco sociocultural, sin el cual no pueden comprenderse ni sus rasgos psicológicos ni sus rasgos culturales" (Young, 1986: 201-202).

Conviene detenerse aquí en el uso de tres términos por parte de Young. Primero, "símbolos", que vienen a ser tanto la palabra (escrita o hablada), como la imagen y la acción (digamos, 
un mitin); segundo, “sugestión”, que según Campbell (2004: 31) es "el intento de inducir en otros la aceptación de una creencia específica sin proporcionar evidencia ni base lógica alguna para su aceptación, exista o no exista dicha base"; y tercero, "marco sociocultural", en alusión a las condiciones en las que se encuentra la audiencia. Conocer este último factor es clave ${ }^{1}$.

Theodore Newcomb aclara que la propaganda es "todo intento sistemático, por medio de la comunicación de masas, de influir en las actitudes. Esos intentos, contrariamente a las nociones populares, no siempre echan mano de la falsedad. La propaganda y el engaño no son sinónimos" (ápud Parra, 1989: 22-23). Propaganda sería, por ejemplo, un campaña radial que enseña a los escuchas hábitos de higiene. Sin embargo, Campbell (2004, 15-16) explica la limitación de estos intentos de definición:

"La razón obvia para ampliar la definición original es que el propagandista no hace siempre algo tan definido como intentar difundir una determinada doctrina o práctica, porque muy a menudo (como en la propaganda de guerra) lo único que intenta es suscitar fuertes emociones de odio o aprobación a favor o en contra de otro grupo por motivos de conveniencia, estrategia o simple codicia [...] La argumentación desapasionada utiliza una técnica totalmente distinta; cuando Sócrates, al hacer preguntas en vez de proporcionar respuestas preparadas a los problemas planteados por sus discípulos, los llevaba a descubrir la verdad por sí mismos, ciertamente no hacía propaganda, aunque en el proceso resultaran cambiadas las opiniones de sus discípulos. El propagandista no entra en una argumentación genuina, porque tiene determinadas sus respuestas por adelantado".

Así, un sector de la academia considera la propaganda como algo negativo. El germen de esta corriente está al final de la Primera Guerra Mundial, cuando se descubrió el poder que podían tener las comunicaciones de masas ${ }^{2}$. Campbell (2004: 13-14) señala: "La palabra ha llegado a adquirir oscuras connotaciones que entrañan todo un proceso frecuentemente siniestro y embustero, basado en el intento deliberado de un individuo o grupo de manipular, a menudo por medios ocultos o solapados, las mentes de otros para sus propios fines". Por su lado, Doob (1972: 415) explica que la

1. Una prueba de que el éxito de la propaganda depende de cuánto se conozca el contexto sociocultural de la audiencia es el nazismo. Campbell (2004: 140 y ss.) cuenta que los artífices de la propaganda nazi tomaron en cuenta los daños que la Primera Guerra Mundial provocó en la autoestima del país germano. Con la finalidad de inocular ideas (como el odio y persecución a los judíos) apelaron a viejos sentimientos alemanes como el autoritarismo y la exaltación obsesiva de la obediencia y de la eficiencia.

2. Durante la Primera Guerra Mundial se utilizó la propaganda para obtener el respaldo de la población, a través de volantes y artículos en la prensa. Los primeros centros de estudio de este fenómeno fueron el Comité de Información Pública de Estados Unidos (1917) y el Departamento de Propaganda Enemiga de Gran Bretaña (1918). 
propaganda es "el intento de lograr afectar las personalidades y controlar la conducta de los individuos hacia fines que no se consideran científicos o que tienen un dudoso valor en la sociedad".

En esta misma línea crítica se ubica Roiz (1994: 32), para quien la propaganda "se caracteriza desde una perspectiva axiológica por sus fines e intenciones de carácter malévolo, falso y manipulado, pudiendo ser desagregadores, al procurar la marginación del contrario". Esta descripción bien podría ajustarse a un régimen comunista como la Unión Soviética (o la actual Corea del Norte), en el que los medios de comunicación estuvieron fuertemente controlados por el gobierno. No obstante, Chomsky asegura que puede haber propaganda del mismo calibre en un régimen liberal:

\begin{abstract}
"Resulta mucho más difícil advertir la actuación de un sistema propagandístico cuando los medios de comunicación son privados y no existe censura formal; en particular cuando tales medios compiten activamente, atacan y exponen con cierta periodicidad los errores del gobierno y de las corporaciones, y se autocalifican enérgicamente de portavoces de la libertad de expresión y de los intereses generales de la comunidad. Lo que ya no es tan evidente (y sigue sin discutirse en los medios de comunicación) es la naturaleza limitada de tales críticas, así como la inmensa desigualdad de los recursos de que disponen y el efecto que tal desigualdad produce tanto en el acceso a una organización de medios de comunicación privada como en su funcionamiento y actuación" (Chomsky y Herman, 2001: 21).
\end{abstract}

La propaganda, en el fondo, presenta dos características principales. Primero, la existencia de dos partes en conflicto. Campbell (2004: 16) remarca que "en tanto está a favor de la creación de determinadas actitudes, el propagandista está necesariamente en contra de la creación de otras". Y segundo, la limitación de su poder sobre la gente. Como recuerda Roiz (1994: 37), "no se pueden comprender los efectos tan perjudiciales que ha tenido en determinadas épocas, países y circunstancias la propaganda, sin asociarlas con otras formas de coacción paralelas, unas veces simbólica (determinado tipo y contenidos de la educación), otras veces reales (como el control policiaco)”.

Se podría concluir que la propaganda es un tipo de persuasión que busca que las personas acepten, de forma acrítica, opiniones políticas, ideológicas o religiosas, para luego realizar ciertas acciones; valiéndose de cualquier medio.

Los procedimientos que usa la propaganda para cumplir su objetivo suelen repetirse en tiempos y lugares. Son principios surgidos durante el siglo pasado, pero que hoy tienen plena vigencia. A continuación detallamos los principales: 
Figura 1: Técnicas de propaganda según James Campbell.

\begin{tabular}{|l|l|}
\hline $\begin{array}{l}\text { El empleo de } \\
\text { estereotipos }\end{array}$ & $\begin{array}{l}\text { Por ejemplo, asociar a alguien de tez blanca con valores como la suavidad y la educación; } \\
\text { y a alguien de tez oscura con antivalores como la brusquedad y la ignorancia. }\end{array}$ \\
\hline $\begin{array}{l}\text { La sustitución } \\
\text { de nombres }\end{array}$ & $\begin{array}{l}\text { Reemplazar términos neutrales por términos cargados de connotación ya sea favorable o } \\
\text { desfavorable. Por ejemplo, en vez de decir "socialista", decir "rojo". }\end{array}$ \\
\hline Selección & $\begin{array}{l}\text { Elegir dentro de un conjunto de hechos aquellos que permitan construir un discurso } \\
\text { favorable. }\end{array}$ \\
\hline $\begin{array}{l}\text { Mentira } \\
\text { descarada }\end{array}$ & $\begin{array}{l}\text { Por ejemplo, denunciar que un candidato presidencial ha sido violador de niños con } \\
\text { pruebas fraguadas. }\end{array}$ \\
\hline Repetición & Repetir una frase tantas veces al punto que empiece a ser aceptada por el público. \\
\hline Afirmación & Aseverar que algo es de determinado modo sin dar razones. \\
\hline $\begin{array}{l}\text { Señalar al } \\
\text { enemigo }\end{array}$ & $\begin{array}{l}\text { Lanzar un mensaje ofensivo a un enemigo real o imaginario, a quien culpamos de haber } \\
\text { frustrado los deseos de los receptores. }\end{array}$ \\
\hline $\begin{array}{l}\text { La alusión a } \\
\text { la autoridad }\end{array}$ & Recurrir a una autoridad profesional, científica, religiosa o política que valide nuestra tesis. \\
\hline
\end{tabular}

Fuente: Campbell (cf. 2004: 32-36).

Domenach, por su lado, resalta las diferencias existentes entre la propaganda y la contrapropaganda:

Figura 2: Diferencias entre la propaganda y la contrapropaganda, según Jean-Marie Domenach.

\begin{tabular}{|c|c|}
\hline \multicolumn{2}{|r|}{ REGLAS DE PROPAGANDA } \\
\hline $\begin{array}{l}\text { Simplificación } \\
\text { y enemigo } \\
\text { único }\end{array}$ & $\begin{array}{l}\text { Polarizar un conflicto entre la esperanza que representa nuestro bando y el fracaso que } \\
\text { representa el bando enemigo }{ }^{3} \text {, e individualizar a este en una persona con el fin de evitar el } \\
\text { debate de ideas. }\end{array}$ \\
\hline $\begin{array}{l}\text { Exageración y } \\
\text { desfiguración }\end{array}$ & $\begin{array}{l}\text { Ofrecer la información clave cargada de una connotación positiva o negativa. Por ejemplo, } \\
\text { destacar datos favorables a nuestra causa, así estos sean dudosos. }\end{array}$ \\
\hline Orquestación & $\begin{array}{l}\text { Repetir un mismo tema bajo formas diversas con el fin de llegar a públicos distintos. Por ejemplo, } \\
\text { criticar a X en diversas secciones de un diario, desde la portada hasta el humor gráfico. }\end{array}$ \\
\hline Transfusión & $\begin{array}{l}\text { Apelar a los prejuicios, temores y rencores del receptor con el objetivo de que se identifique } \\
\text { con nosotros. }\end{array}$ \\
\hline $\begin{array}{l}\text { Unanimidad } \\
\text { y contagio }\end{array}$ & Crear consenso en torno a cierto tema hablando en nombre de la mayoría ${ }^{4}$. \\
\hline
\end{tabular}

3 Al respecto Roiz (1994: 54-55) señala que "es indudable la eficacia de convicción que produce plantear dos posiciones antagónicas dentro del orden social: la buena/la mala; la positiva/la negativa; la nuestra/la suya; el orden/el desorden [...] Así se puede exigir al receptor la necesaria e ineludible elección entre dos campos: el nuestro impregnado de verdad y valores positivos, y el de ellos lleno de falsedad, maldad y valores negativos".

4 El uso del pronombre nosotros "adquiere una gran fuerza coactiva porque reafirma simbólicamente la identificación del receptor con intereses presuntamente comunes" (ibidem: 16). 


\section{REGLAS DE CONTRAPROPAGANDA}

- Reconocer los temas del adversario (ordenarlos de acuerdo a la importancia que tienen).

- Atacar los puntos débiles (empezar por la idea más fácil de rebatir).

- Cuando la propaganda adversaria es poderosa, no atacarla de frente.

- Atacar y desdeñar al adversario (privilegiando el argumento personal por encima del racional).

- Demostrar que la propaganda del adversario se contradice con los hechos.

- Ridiculizar al adversario (usando bromas e historias cómicas breves).

- Buscar que predomine nuestro "clima de fuerza" (nombrando varias veces al enemigo para herirlo).

Fuente: Domenach ( $c f$. 1993: 47-89).

Durandin ( $c f .1983: 11$ y ss.) ha dedicado buena parte de su carrera a estudiar una sola técnica propagandística: la mentira. Para este autor se trata del procedimiento más eficaz, pues al camuflar la intencionalidad del emisor pone en estado de máxima vulnerabilidad a la audiencia. Definida como "la acción de dar voluntariamente a un interlocutor una visión de la realidad diferente de la que uno mismo tiene por verdadera", la mentira puede tratar sobre el persuasor, el enemigo o el entorno. Asimismo, puede tener como herramientas la palabra, la imagen, el falso personaje, la falsas acción, entre otras.

Figura 3: Operaciones de la mentira, según Guy Durandin.

\begin{tabular}{|c|c|c|}
\hline \multirow{3}{*}{$\begin{array}{l}\text { Supresiones: } \\
\text { Hacer creer que } \\
\text { algo que existe, } \\
\text { no existe. }\end{array}$} & Omisión & Ocultar información al interlocutor. \\
\hline & Negación & $\begin{array}{l}\text { Afirmar que algo verdadero que se dijo sobre un hecho que nos } \\
\text { concierne es falso, y acusar de mentirosa a la fuente. }\end{array}$ \\
\hline & $\begin{array}{l}\text { Supresiones } \\
\text { materiales }\end{array}$ & $\begin{array}{l}\text { Esconder o destruir pruebas, como huellas y documentos, que } \\
\text { prueben nuestro delito. }\end{array}$ \\
\hline \multirow{3}{*}{$\begin{array}{l}\text { Adiciones: Hacer } \\
\text { creer que algo que } \\
\text { no existe, existe. }\end{array}$} & Disimular un plan & $\begin{array}{l}\text { Concebir y poner en marcha planes falsos para distraer al } \\
\text { enemigo. }\end{array}$ \\
\hline & $\begin{array}{l}\text { Embellecer o } \\
\text { deslucir un objeto }\end{array}$ & $\begin{array}{l}\text { Elogiar el campo amigo con falsas noticias favorables y deslucir } \\
\text { el campo enemigo con falsas noticias desfavorables. }\end{array}$ \\
\hline & $\begin{array}{l}\text { Justificar una } \\
\text { acción agresiva }\end{array}$ & $\begin{array}{l}\text { Inventar información sobre presuntos desórdenes en el campo } \\
\text { enemigo para justificar nuestra intervención. }\end{array}$ \\
\hline
\end{tabular}




\begin{tabular}{|l|l|l|}
\hline \multirow{2}{*}{$\begin{array}{l}\text { Deformaciones: } \\
\begin{array}{l}\text { Deformar algo que } \\
\text { existe. }\end{array}\end{array}$} & $\begin{array}{l}\text { Exagerar (por ejemplo, las pérdidas del enemigo en una batalla) } \\
\text { y minimizar (por ejemplo, las pérdidas propias). }\end{array}$ \\
\cline { 2 - 3 } & $\begin{array}{l}\text { Cualitativas } \\
\text { Denominación } \\
\text { por lo contrario }\end{array}$ & $\begin{array}{l}\text { Por ejemplo, filtrar un mensaje nuestro en el campo enemigo como } \\
\text { si fuera proveniente de una fuente amiga (propaganda negra). }\end{array}$ \\
\cline { 2 - 3 } & $\begin{array}{l}\text { Deformar tanto un objeto que parezca contrario a lo que en } \\
\text { realidad es. Por ejemplo, devolverle una acusación al enemigo } \\
\text { poniéndonos en plan de víctimas. }\end{array}$ \\
\hline
\end{tabular}

Fuente: Durandin ( $c f .1983: 77$ y ss.)

Finalmente, Chomsky propone un modelo de propaganda basado en cinco filtros que retienen la información y los comentarios "disidentes" (figura 4). Este autor ( $c f .2001$ : 71) explica que las noticias que pasan por estos filtros son las que provienen del establishment político o económico, mientras que las que se quedan estancadas proceden de "los disidentes y los débiles".

Figura 4: Modelo de propaganda, según Noam Chomsky.

\begin{tabular}{|l|l|}
\hline La propiedad & $\begin{array}{l}\text { Son los dueños del medio de comunicación, que suelen tener intereses económicos en } \\
\text { este y otros giros de negocio. }\end{array}$ \\
\hline La publicidad & $\begin{array}{l}\text { Los anunciantes, al ser la principal fuente de ingresos del periodismo, influyen en los } \\
\text { contenidos. }\end{array}$ \\
\hline Las fuentes & $\begin{array}{l}\text { Las oficinas de prensa estatales y privadas buscan trasladar su propia agenda a la } \\
\text { prensa. }\end{array}$ \\
\hline La intimidación & $\begin{array}{l}\text { Hay agentes estatales y privados dispuestos a emplear la violencia simbólica para } \\
\text { mantener en raya a los periodistas. }\end{array}$ \\
\hline El anticomunismo & $\begin{array}{l}\text { Es el principio de la política occidental, que hace que la prensa sirva a los intereses de la } \\
\text { "caza de rojos". }\end{array}$ \\
\hline
\end{tabular}

Fuente: Chomsky y Herman (cf. 2001: 22 y ss.)

\section{La prensa, actor político}

Ahora exploraremos la relación entre periodismo y política. Borrat (1989: 10) sostiene que el periódico independiente de información general es un verdadero actor político de naturaleza colectiva, cuyo ámbito de actuación es el de la influencia, no el de la conquista del poder institucional o la permanencia en él (figura 5), entendiéndose por actor político a todo ente colectivo o individual capaz de afectar el proceso de toma de decisiones en el sistema político. Así, el periodismo comparte con el gobierno, los partidos políticos y los grupos de interés la facultad de influir en los acontecimientos públicos. 
Figura 5: Configuración del periódico como actor político.

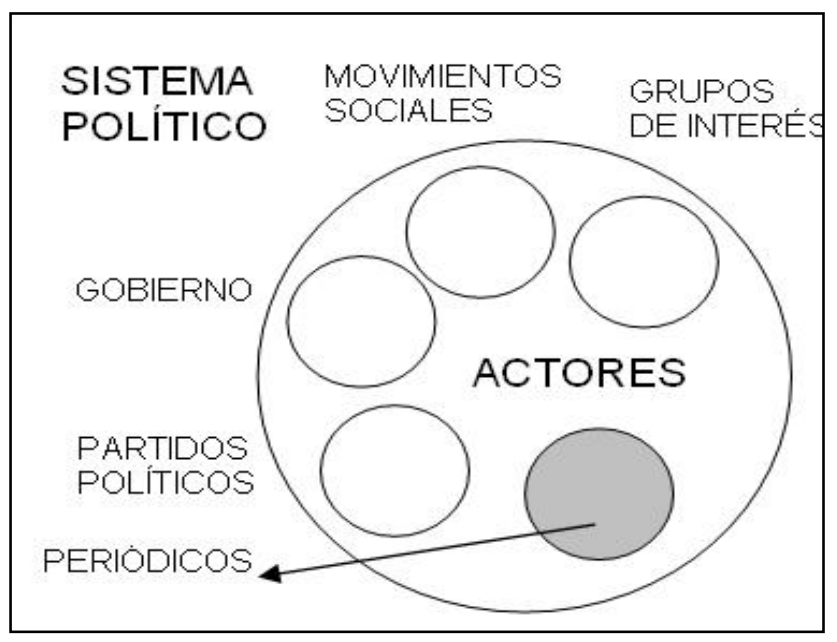

Fuente: Borrat (1989: 10).

De acuerdo con Borrat, el periódico como actor político tiene actuaciones "públicas" y "no públicas". Las primeras son el encuentro con los lectores y tienen lugar en el quiosco, y las segundas son todas las comisiones y reuniones de edición que hacen los periodistas antes de informar. Este autor (1989: 33) recalca que la elaboración de la información y la opinión en un medio de comunicación está influida por la posición política del emisor:
"Cuando la línea política de un periódico se hace explícita, su escenario es el editorial. De manera implícita, en cambio, la línea política recorre y modela todo el temario publicado: entendida como la estrategia del periódico, decide inclusiones, exclusiones y jerarquizaciones tanto en los escenarios de los relatos informativos como en los escenarios de los comentarios políticos [...] La articulación de esta línea con aquellas dos señales (trato justo y equilibrado, y pluralismo) no es fácil, implica tensiones y suele ser un factor de conflictos que involucran al propio periódico: conflictos por el trato injusto y desequilibrado que el periódico hace de los actores de la información y conflictos por ausencia o insuficiencia de pluralismo en los autores de los comentarios que el periódico publica".

Al igual que Borrat, Muraro ( $c f$. 1998: 63 y ss.) concibe el periodismo como parte del sistema político. Este autor llama al sistema político "espacio público político" e incluye en él a políticos, periodistas, intelectuales, representantes de las corporaciones, lobbistas y líderes de movimientos sociales; a todos los considera "notables". Estos actores compiten entre sí no sólo para establecer reglas y soluciones, sino también para obtener reconocimiento público. 
El mencionado autor grafica su idea con un grupo de conjuntos y subconjuntos (figura 6). Fuera de juego están los "excluidos", como llama a aquellos que no hablan el idioma nacional o viven en lugares aislados. En el conjunto más grande están los “ciudadanos peor informados", que son los que no muestran interés por la política. En el conjunto mediano están los "ciudadanos mejor informados", que son los que sí muestran interés por la política. Y en tres círculos pequeños están los "periodistas", la "élite política" y la "clase política". Cabe anotar que mientras la "élite política" la forman el presidente de la República, los ministros, los congresistas, entre otras autoridades elegidas, la "clase política" la forman los funcionarios de carrera, asesores, dirigentes, entre otros miembros secundarios del sistema político.

Figura 6: El periodismo en el espacio público político.

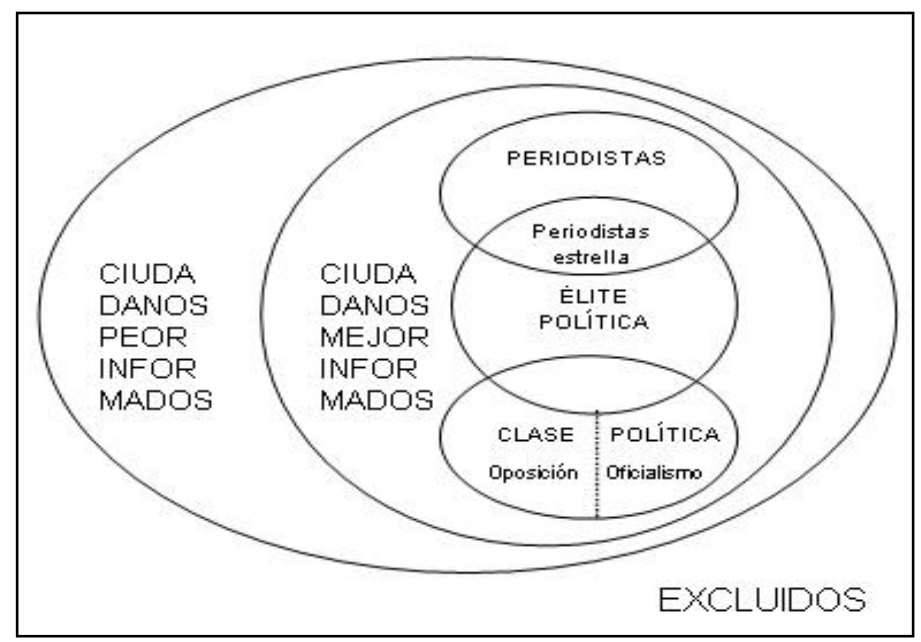

Fuente: Muraro (cf. 1998: 63 y ss.)

Es interesante cómo Muraro (1998: 69) superpone los conjuntos "periodistas" y "clase política", creando un subconjunto denominado "periodistas estrella". Se trata de periodistas "cuyas opiniones tienen peso en la conformación de las corrientes de opinión, en tanto que los otros no son sino modestos redactores o recopiladores de información relativamente anónimos, cuyos comentarios sobre la actualidad no tienen, normalmente, mayor trascendencia"s. Los periódicos normalmente asignan un rol preponderante a los temas políticos:

"La información política cubre normalmente la portada de los diarios y es la más frecuente en la portada de los semanarios, se

\footnotetext{
5. Esta distinción es importante pues permite hacer estudios serios sobre los efectos de la prensa. No es lo mismo medir el impacto de un periódico, canal de televisión o estación de radio como un ente abstracto que hacerlo en términos de emisores específicos.
} 


\begin{abstract}
desarrolla en las secciones frontales y permanentes de diarios y semanarios, destinados a la política interna del propio país y de otros países y a las relaciones internacionales, da lugar a la mayoría de los comentarios en las páginas de opinión, confirma su primacía en las columnas, el humor gráfico, las revistas de la prensa, las cartas de los lectores. Más todavía: la política invade con mayor o menor frecuencia las otras áreas y secciones que, en el periódico de información general, parecen otros tantos correlatos de los sistemas social, económico y cultural: Sociedad, Economía, Cultura, Espectáculos, Deportes" (Borrat, 1989: 40).
\end{abstract}

Ahora examinemos la relación entre periodistas y políticos. Esta puede ser de cuatro tipos: $a$ ) de dependencia, b) de enfrentamiento, c) de sumisión y d) de reemplazo. Sobre la primera hay que decir, de la mano con Muraro ( $c f .1998: 70$ y ss.), que los políticoscandidatos requieren la mediación de la prensa para llegar a sus gobernados-votantes, y los medios necesitan la complicidad de los políticos para elaborar sus informaciones 6 Conejeros (2000: 231-232) se pregunta: “¿Hay otro profesional que viva más de la política que el redactor político? ¿Hay otra actividad que no dependa tanto de los avatares de la política como el periodismo?”.

El segundo tipo de relación tiene que ver con la labor de fiscalización que debe ejercer la prensa. Esto se hace más palpable en el periodismo de investigación, cuyos hallazgos desencajan a funcionarios y empresarios que ven cómo sus irregularidades son comentadas por la ciudadanía. Aquí se produce una especie de ecuación matemática: el desprestigio de los políticos contribuye al prestigio de los periodistas. Por ello, señala Herrero (1996: 50), la interacción entre políticos y periodistas suele ser "tensa y crispada". La autora recuerda, además, que a lo largo de la historia el poder político ha buscado anular la libertad de la prensa. Uno de los mecanismos favoritos ha sido el cierre de medios. Otro, más propio de las sociedades democráticas, es la corrupción de los empresarios periodísticos.

La antítesis de la vigilancia es la sumisión, el tercer tipo de relación periodismo-política. Cabe indicar que el periodismo nació subordinado a intereses particulares: los periódicos, antes de la Primera Guerra Mundial, solían ser fundados por políticos que necesitaban hacer propaganda. Esta visión corresponde a la etapa de la historia conocida como "periodismo ideológico"7. La sumisión es la falta de vigilancia por parte de la prensa, y tiene varios

6. En esa línea, Fernández Bogado (2000: 222) afirma que "no es casual que más del 80\% de la agenda informativa de los periódicos norteamericanos está establecida por políticos o por filtraciones políticas".

7. Martínez Albertos (cf. 2007: 265-266) sostiene que el periodismo moderno puede dividirse en tres etapas: el periodismo ideológico, el periodismo informativo y el periodismo de explicación. Partiendo de los aportes que ha hecho Ángel Benito al respecto, Martínez Albertos explica que, a lo largo de la historia, los periodistas han tenido distintas actitudes. Primero fue el periodismo ideológico, que duró hasta el fin de la Primera Guerra Mundial (1918) y se caracterizó por ser "doctrinal y moralizador, con ánimo proselitista, al servicio de ideas políticas o religiosas". Luego apareció el periodismo informativo, que está fundamentado en el relato y no en 
motivos: intereses empresariales, negligencia y desapasionamiento. La actitud acrítica es el sueño dorado de los agentes de prensa.

El último tipo de relación posible entre periodismo y política es el reemplazo y se produce cuando la prensa hace lo que le corresponde a la administración pública:

"Mucho de la politización de nuestros medios informativos y de los periodistas viene de una situación distorsionada en nuestras jóvenes democracias donde las instituciones o son frágiles o cuasiinexistentes. De ahí que las denuncias que deberían canalizarse al departamento de quejas de un ente público terminan en la radio o en los diarios por la frustración que supone al contribuyente el no lograr la reparación deseada o tan siquiera que lo escuchen [...] Surge así la prensa como un factor correctivo y a veces ella asume la función de los partidos, la del departamento de quejas de un ministerio o la de simple correa de transmisión entre el reclamo del ciudadano y la acción reparadora [...] No es bueno que la labor de la prensa se reduzca a suplir lo que otros entes deberían realizar. Por este camino se pierde la credibilidad ciudadana hacia las instituciones" (Fernández Bogado, 2000: 222-223).

Es tiempo electoral cuando la prensa está más relacionada con la política. ¿Cómo debe comportarse el periodismo en este contexto? Aguilera (1991: 146) cree que "no se trata de conducir y presionar a los electores respecto a unas ideas, un líder o un partido, sino de ofrecerles una visión clara, concisa y orientadora, pero en ningún momento con fines propagandísticos"8.

El autor (ibídem: 149-150) recalca que en tiempo electoral "la cobertura de las noticias generadas por los partidos es el resultado de la estrategia calculada por los directores de campaña de los candidatos, que intentan con todos los medios a su alcance encauzar las agenda-setting de los periodistas, a los que proveen de abundantísima información y conceden inusitadas facilidades sobre temas y asuntos que convienen al partido". Borrat (1989: 157-158) asume que la prensa puede tener preferencias, pero que esto no debe menoscabar la tolerancia:

el comentario, y que empezó hacia 1870 en Inglaterra. Tras coexistir durante algunas décadas con la prensa ideológica, este esquema se trasladó a Estados Unidos. Finalmente, el periodismo de explicación, surgido hacia el fin de la Segunda Guerra Mundial (1945), se ha caracterizado por contener una dosis equilibrada de información y opinión. Sus géneros son el reportaje en profundidad y la crónica.

8. Oficialmente, el gobierno peruano (ONPE, 2006: 54) le atribuye a la prensa cuatro funciones en tiempo electoral: "Informar contribuyendo a que la población tome decisiones a partir del análisis y la reflexión; generar opinión promoviendo el debate público, haciendo énfasis en el análisis y las propuestas de los diferentes partidos; vigilar de manera permanente el comportamiento de cada uno de los actores electorales y el cumplimiento de sus corresponsabilidades; y difundir mensajes educativos que aseguren un voto de calidad y promuevan la participación masiva de la ciudadanía". 
"Reconocer afinidades y cercanías no es, como en la prensa del Estado, de partidos, de sindicatos o de la Iglesia, reconocer dependencias respecto de actores externos a la propia empresa editora. Tampoco es señalar una coincidencia plena o una alianza estable. Hasta en los casos de mayor cercanía con las posiciones de un partido, la prensa independiente necesita destacar una flexibilidad en sus posiciones que puede llegar a la alternancia de premios y castigos al mismo actor político".

Las afinidades políticas de un periódico dependen de su línea editorial. Sohr (1998: 225) define la línea editorial como "el cuerpo de valores y creencias al que adhiere un medio de comunicación. En general, estos puntos de vista se expresan en los espacios de opinión (páginas editoriales). Suele estar dictada, por lo menos en sus líneas más gruesas, por los propietarios, que designan a un director y editores y jefes afines".

Desde una posición crítica, Chomsky y Herman (2001: 11) señalan que el periodismo sirve para "movilizar el apoyo en favor de los intereses especiales que dominan la actividad estatal y privada". Sohr (1998: 108) recuerda que "los medios de comunicación influyentes son grandes empresas. Y sus propietarios comparten las opiniones del empresariado, quienes defienden el statu quo político en el que han prosperado. Esta tendencia se ve reforzada por el avisaje, que forma parte importante del ingreso de los medios ${ }^{9}$. Auspiciadores y avisadores son, por norma, refractarios a temas conflictivos como son la investigación y denuncia de los abusos del poder político y económico". Brian McNair destaca que "el principal mecanismo a través del cual los propietarios pueden ejercer su control es su poder de nombrar a personal clave, especialmente a los editores jefes, que se convierten en la voz del propietario en la sala de redacción, asegurándose que la 'independencia' periodística se ajuste a la línea editorial preferida" (ápud Sohr, 1998: 108).

Borrat ( $c f$. 1989: 47 y ss.) también analiza los intereses corporativos del periodismo. Para este autor en un medio de comunicación existe un esquema vertical formado por tres estamentos: el poder empresarial, los "mandos de los subsistemas" y los "ejecutores". El primero está formado por la cúpula o "centro de poder fáctico" que define las estrategias específicas a corto, mediano y largo plazo; el segundo está integrado por el director y los jefes de las distintas áreas, y es el que ejecuta las estrategias definidas por la cúpula, aunque, por su alto grado de especialización, goza de cierta autonomía; y el tercero, constituido por una masa anónimo de reporteros, cumple las disposiciones de los mandos intermedios.

\footnotetext{
9. Sobre la relevancia que ha adquirido la publicidad en el periodismo, Habermas (1997: 213) dice que "la historia de los grandes periódicos diarios en la segunda mitad del siglo XIX prueba que la prensa se hace manipulable en relación a su grado de comercialización. Puesto que la venta de la parte destinada al reclamo publicitario está interrelacionada con la venta de la parte confeccionada por la redacción, la prensa, hasta entonces institución de las personas privadas como público, se convierte ahora en la institución de determinados miembros del público como personas privadas; esto es, en la puerta de entrada a la publicidad de intereses privados privilegiados".
} 
Es interesante que Borrat ubique al director fuera del grupo decisorio real y dentro de los mandos medios, pues se tiende a pensar que el director conduce todos los hilos de un medio. Este autor (1989: 50) explica que el encargado formal de un periódico nunca deja de depender de la junta de accionistas:
"Según lo que ese núcleo decida, la dirección del periódico podrá ser incluida en ese centro de poder o quedar excluida de él; podrá ser investida o no de facultades propias para decidir por sí y ante sí ciertas estrategias específicas de cuyo resultado dará cuenta después a la empresa. Pero es la élite del poder empresarial la que en todo caso ejerce el mando supremo".

Los intereses corporativos tienen que ver, en el fondo, con una transformación radical del periodismo: la noticia empezó a ser una mercancía. Según Kapuscinski (2003: 13 y ss.; y 23-24), este cambio empezó a inicios de la década de 1980:

\begin{abstract}
"Al descubrimiento del enorme valor económico de la noticia se debe la llegada del gran capital a los medios de comunicación. Normalmente el periodismo se hacía por ambición o ideales, pero de repente se advirtió que la noticia era un gran negocio, que permitía ganar dinero pronto y en grandes cantidades. Eso cambió totalmente nuestro ambiente de trabajo [...] Eso creó una brecha entre los dueños y los gerentes de los medios y nosotros, los periodistas, porque ellos persiguen otros intereses y objetivos. Hoy al cronista que llega de hacer una cobertura su jefe no le pregunta si la noticia que trae es verdadera, sino si es interesante y si la puede vender. Este es el cambio más profundo en el mundo de los medios: el remplazo de una ética por otra [...] Por verdadera que sea una información, carecerá de valor si no está en condiciones de interesar a un público que, por otro lado, es crecientemente caprichoso ${ }^{10}$.
\end{abstract}

Como consecuencia de este viraje, la prensa se ha hecho de un poder equiparable al de la clase política. Kapuscinski (2003: 25) recuerda que "en el pasado los medios se instalaban en edificios de segunda categoría y disponían de espacios estrechos y mal acondicionados donde se afanaban los periodistas, casi siempre mal vestidos y sin dinero en el bolsillo. Hoy un canal de televisión perteneciente a las grandes cadenas ocupa suntuosos palacios llenos de mármoles y espejos, por cuyos silenciosos pasillos el visitante es conducido por deslumbrantes asistentes. En estos ámbitos se concentra el poder que antes ostentaban sólo los jefes de Gobierno. Actualmente el poder está en manos de quien posea un estudio de televisión, un diario, una radio".

\footnotetext{
10. Sohr (cf. 1998: 108) intenta poner en perspectiva esta consideración al afirmar que el buen periodismo siempre será rentable. Los periódicos que publican primicias y van al fondo de los temas se convierten, según este autor, en referentes obligados de lectura, por lo que generan altos niveles de ventas.
} 
Ramonet ( $c f$. 1998: 31 y ss.) coincide con Kapuscinski en cuanto a la nueva concentración de poder en manos de los medios. Este autor agrega que, en la actualidad, la prensa ha dejado de ser el "cuarto poder" (como se le suele llamar para oponerlo al ejecutivo, legislativo y judicial) debido a su cercanía, cada vez mayor, con las clases políticas y empresariales. Así, propone replantear el orden tradicional de poderes para ubicar primero al económico, segundo al mediático y tercero al político. Ramonet (1998: 32) piensa que "si se quisiera clasificar los poderes, como se hacía en los años veinte y treinta, se vería que los media han ascendido, han ganado posiciones y hoy se sitúan como instrumento de influencia (que puede hacer que las cosas cambien) por encima de un buen número de poderes formales". Este cambio proviene del surgimiento en todo el orbe de grandes conglomerados mediáticos que agrupan a empresas periodísticas.

Esta situación suele generar conflictos éticos en las salas de redacción, como los descritos por Ryszard Kapuscinski. Se trata de un choque de lógicas contrapuestas: por un lado, los propietarios-empresarios buscan generar la máxima rentabilidad con la información que ofrecen; y por el otro, los periodistas están preocupados en vigilar el poder político y económico. Se podría decir, así, que en una empresa periodística cohabitan dos tipos de personas: la que cuida sus propios intereses y la que cuida los de la nación. Verbitsky (1997: 16) explica así lo que considera la misión primordial de la prensa:

"Periodismo es difundir aquello que alguien no quiere que se
sepa, el resto es propaganda. Su función es poner a la vista lo
que está oculto, dar testimonio y, por lo tanto, molestar. Tiene
fuentes, pero no amigos. Lo que los periodistas pueden ejercer,
y a través de ellos la sociedad, es el mero derecho al pataleo, lo
más equitativa y documentadamente posible. Criticar todo y a
todos. Echar sal en la herida y guijarros en el zapato. Ver y decir
el lado malo de cada cosa, que del lado bueno se encarga la
oficina de prensa, de la neutralidad los suizos, del justo medio
los filósofos y de la justicia los jueces. Y si no se encargan, ¿qué
culpa tiene el periodismo?".

\section{El periodismo ideológico en el Perú}

En el apartado anterior mencionamos la etapa de la historia de la prensa conocida como "periodismo ideológico", un antecedente clave para entender el actual comportamiento de los medios y su presunta "propagandización".

En el Perú los periódicos nacieron con claras vocaciones ideológicas o partidistas. Peirano y otros ( $c f .1978: 12$ y ss.) cuentan que la prensa peruana apareció durante el Virreinato, cuando la burguesía criolla necesitaba difundir sus puntos de vista sobre las reformas que debían implantarse. Periódicos como el Diario de Lima (1790) se posicionaron como bastiones alternativos a las publicaciones españolas. 
En el siglo XIX apareció la prensa de masas, aunque todavía afecta a las ideologías. $E l$ Comercio, fundado en mayo de 1839, se vinculó rápidamente al Partido Civil, que por entonces representaba a la oligarquía. Como recuerdan Peirano y otros, este diario se opuso abiertamente a todo gobierno de apariencia democratizante, como el de Nicolás de Piérola, y respaldó todos los regímenes conservadores, incluso aquellos que se impusieron en el poder. Gargurevich ( $c f .1991$ : 146) detalla, por ejemplo, que El Comercio apoyó el golpe militar de Luis Sánchez Cerro contra Augusto B. Leguía en agosto de 1930. Entonces ya el periódico contaba con enemigos políticos, el principal de los cuales era el APRA ${ }^{11}$.

Más tarde el decano de la prensa nacional justificó el golpe de Estado de Manuel Odría, que gobernó entre 1948 y 1956. En realidad, lo respaldó toda la prensa conservadora, donde también destacaba el diario La Prensa, fundado en 1903 por Pedro de Osma, pero controlado por Pedro Beltrán desde 1930. Gargurevich (1991: 155-156) recuerda que este periódico saludó el golpe de Odría en su editorial del 30 de octubre de 1948:

"En las manos limpias y vigorosas de los miembros de los institutos armados están, por ahora, los destinos nacionales. Ellos, una vez más, nos han dado un ejemplo de lealtad al país, de amor a sus instituciones [...] Se han unido para realizar el salvador esfuerzo que va a redimirnos del oprobio de tres años de predominio de una secta que reniega de Dios, no siente amor a la Patria y escarnece las más sagradas leyes. Tenemos que aprovechar esta hermosa lección".

El general Manuel Odría correspondió este gesto nombrando a Beltrán como presidente del Banco Central de Reserva. Por entonces el director de La Prensa, dueño de una hacienda en Cañete, ya se había hecho conocido como vocero de los terratenientes. Lo interesante del caso es que, a la vez que recibía críticas por su sesgo conservador, Beltrán era considerado pionero de la objetividad periodística ${ }^{12}$.

El primer tabloide peruano, La Crónica, fue fundado por Clemente Palma en 1912. Al poco tiempo desapareció y reapareció en 1956, para apuntalar la candidatura presidencial de Manuel Prado. El periódico era propiedad de la familia Prado, que tenía intereses repartidos

11. La rivalidad entre El Comercio y el APRA surgió desde la aparición misma del partido, que empezó a abogar por la alteración del statu quo a favor de las clases populares, y llegó a su punto más álgido con el asesinato de un miembro de la familia Miró Quesada por un militante aprista. Este hecho llevó a que el diario se opusiera ferozmente al gobierno del oligarca Manuel Prado (1955-1962), que mantenía una alianza con el APRA ( $c f$. Peirano y otros, 1978: 12 y ss.)

12. Beltrán habría sido el primer director de un periódico en hablar de la "pirámide invertida", ese esquema de redacción que ofrece lo más importante, gradualmente, desde la primera hasta la última línea. Según Gargurevich (1991: 176), "en realidad fue quien tuvo la energía y la posibilidad de aplicarlas, pero ya eran conocidas por los profesionales y especialmente por los profesores de las nuevas escuelas de periodismo". La Prensa buscó parecerse al The New York Times y al Herald Tribune, separando los relatos de los comentarios. Gargurevich cuenta que "Pedro Beltrán solía decirles a los editores: 'La página editorial es mía, el resto es de ustedes', marcando una diferencia radical entre noticias y opinión. Una presencia así no podía menos que influir en el resto del periodismo” (ibidem: 177). 
por la banca, el sector inmobiliario, las compañías de seguros, entre otros. No era raro que el local de La Crónica sirviera en ocasiones como local de campaña.

De este modo, la prensa se tornaba el complemento ideal de aquel que emprendía una carrera política o buscaba hacer negocios. Allí está el caso del diario Correo, fundado por el magnate pesquero Luis Banchero Rossi en 1961. Según Peirano y otros (1978: 17), "el periodismo le ofrecía el medio para divulgar su proyecto político, de presionar sobre los diversos grupos de poder". Tras la muerte de Banchero, la dirección del periódico fue asumida por su socio Enrique Agois.

El diario Expreso, creado por el terrateniente Manuel Mujica Gallo a fines de 1960, tuvo inicialmente una orientación popular. Cuando su primer director, José Antonio Encinas, le pidió al dueño hablar sobre la línea editorial, esta se definió como una lucha contra la oligarquía $^{13}$. Así, el diario respaldó el primer gobierno de Belaunde (1963-1968). Al poco tiempo, Manuel Ulloa adquirió Expreso, despidió a Encinas y giró la línea hacia la derecha.

Un momento neurálgico en el periodismo peruano fue el gobierno militar de Juan Velasco Alvarado (1968-1975). Velasco sostenía que la prensa había estado en manos de grupos económicos y políticos que habían velado sólo por sus intereses, por lo que era necesario ponerlos al servicio de la nación. Así, desde diciembre de 1969 promulgó una serie de normas orientadas a vigilar y controlar los contenidos mediáticos. El 26 de julio de 1974, el gobierno dispuso la expropiación de los diarios con el Decreto Ley 20681, que en teoría los ponía en manos de "sectores organizados de la sociedad" pero que al final terminaron sirviendo a la "revolución"14.

Uceda (2011) recuerda que, hasta entonces, la prensa peruana había estado dividida en dos bandos irreconciliables:

"El periodismo que heredamos es un periodismo fuertemente marcado por la Guerra Fría, donde hay periodistas de derecha, llamados despreciativamente por los de izquierda 'probeltranistas', o sea que vienen de la tradición de Beltrán y estaban alrededor del diario La Prensa, y periodistas de izquierda, que eran, en buena parte, militantes comunistas o procomunistas. Había, pues, dos formas de hacer periodismo".

A mediados de 1974, se podían reconocer dos grupos periodísticos en pugna: por un lado, La Prensa, El Comercio, Última Hora y Correo, de tendencia conservadora; y por el otro,

13. Expreso nació con el fin de "propugnar reformas que eleven los niveles de vida en las clases populares" y "defender el sistema democrático basado en un régimen de auténtica justicia social" (Peirano y otros, 1978: 18).

14. El artículo 24 del Nuevo Estatuto de Prensa, aprobado por Velasco, dispuso que los periódicos den cabida "en actitud pluralista y dialogante, a los enfoques ideológicos que encuadren dentro de los parámetros de la Revolución Peruana". 
Expreso y La Crónica, de tendencia liberal. Desde entonces, la mayoría de los medios ha respondido a posiciones políticas contrapuestas, cuyas propuestas se exacerban y entran en conflicto durante los procesos electorales. Así, en el Perú, las nociones de periodismo objetivo (que busca la separación de la información y la opinión) han conformado un paréntesis en una historia plagada de ideología.

\section{Periodismo propagandístico}

La interacción entre periodismo y propaganda se debe entender desde tres puntos de vista: a) el histórico, referido al control que han querido ejercer los políticos sobre los medios de comunicación; b) el teórico, alusivo a las investigaciones que arrojan vínculos entre prensa y propaganda; y c) el práctico, que muestra el afán del marketing político por manipular los contenidos periodísticos.

Sobre el primer enfoque, debemos indicar que para los dictadores del siglo pasado el periodismo no era sino una instrumento simbólico que trataron de usar a su favor. Campbell (2004: 171) describe así la situación del "periodismo" en la Unión Soviética:

"El sistema está planteado y opera según una filosofía sujeta a la línea del partido, por lo que su contenido difiere en muchos aspectos del de países no comunistas: apenas existe el concepto de la noticia entendida como la información rápida y objetiva de los acontecimientos de actualidad, siendo reemplazada por la edición selectiva de acontecimientos pasados y presentes interpretados en términos de la ideología soviética”.

Por su lado, Chomsky (2002: 8-9) recuerda la primera operación de propaganda llevada a cabo por un Estado, referida a la campaña a favor de la participación de los Estados Unidos en la Primera Guerra Mundial:

"La población era muy pacífica y no veía razón alguna para involucrarse en una guerra europea; sin embargo, la administración Wilson había decidido que el país tomaría parte en el conflicto. Había, por tanto, que hacer algo para inducir en la sociedad la obligación de participar en la guerra. Y se creó una comisión de propaganda gubernamental, conocida con el nombre de Comisión Creel, que, en seis meses, logró convertir una población pacífica en otra histérica y belicista que quería ir a la guerra y destruir todo lo que oliera a alemán. Los medios utilizados fueron muy amplios [...] Se fabricaron montones de atrocidades supuestamente cometidas por los alemanes, en las que se incluían niños belgas con los miembros arrancados y todo tipo de cosas horribles que todavía se pueden leer en los libros de historia”. 
Dentro del segundo punto de vista (sobre la interacción periodismo-propaganda), destaca la postura de Merrill, Lee y Friedlander (1992: 80), que subraya la posibilidad de hermanar ambos conceptos:
“¿Es el periodismo propagandístico? Sí. Ciertamente no en un sentido absoluto, pero hay mucho de ello. No nos gusta pensarlo, por supuesto. Después de todo, ¿no está el periodismo para ser creído, respeto y para confiar en él? ¿No es el periodismo el negocio de la verdad y no el de la propaganda? A pesar de que la opinión y los editoriales han sido siempre parte del periodismo, la imagen básica o el estereotipo del periodismo (del periodismo informativo, por lo menos) ha sido tradicionalmente el de la objetividad, seguridad y confianza [...] Consideramos a los periodistas como propagandistas en el sentido de que "propagan" sus propias tendencias y opiniones, en un intento deliberado por influir sobre las actitudes y acciones del público".

Los mencionados autores se animan a plantear un conjunto de técnicas de propaganda (figura 7) que se utilizarían en el periodismo:

Figura 7: Técnicas de propaganda periodística.

\begin{tabular}{|l|l|}
\hline $\begin{array}{l}\text { La creación de } \\
\text { estereotipos }\end{array}$ & $\begin{array}{l}\text { Simplificar la realidad de las personas y los hechos, presentándolos de forma } \\
\text { unidimensional. }\end{array}$ \\
\hline $\begin{array}{l}\text { La presentación de } \\
\text { opiniones como hechos }\end{array}$ & Camuflar nuestros juicios de valor como descripciones supuestamente objetivas. \\
\hline $\begin{array}{l}\text { Hablar a través } \\
\text { de otras fuentes }\end{array}$ & Hacer que los otros emitan opiniones que coinciden con las del periodista. \\
\hline $\begin{array}{l}\text { Atribuciones } \\
\text { tendenciosas }\end{array}$ & $\begin{array}{l}\text { Usar adjetivos y adverbios al introducir la cita textual de una fuente para crear } \\
\text { un aura positiva o negativa. }\end{array}$ \\
\hline $\begin{array}{l}\text { Selección de la } \\
\text { información }\end{array}$ & $\begin{array}{l}\text { Dejar de informar ciertos hechos sabiendo que son parte del caso que } \\
\text { reportamos. }\end{array}$ \\
\hline $\begin{array}{l}\text { Control planificado } \\
\text { de la información }\end{array}$ & $\begin{array}{l}\text { Omitir un antecedente importante aparecido en la prensa sobre el caso que } \\
\text { reportamos. }\end{array}$ \\
\hline El uso de etiquetas & Usar palabras con carga opinativa al nombrar una fuente. \\
\hline Autoridad vaga & $\begin{array}{l}\text { Usar formas introductorias ("mucha gente piensa que...”) cuando en realidad es } \\
\text { lo que cree el periodista. }\end{array}$ \\
\hline Objetividad selectiva & Tomar cifras y frases reales para manipularlas. \\
\hline
\end{tabular}




\begin{tabular}{|l|l|}
\hline $\begin{array}{l}\text { Generalizaciones } \\
\text { exageradas }\end{array}$ & Atribuir a todo un grupo las opiniones de uno o dos de sus miembros. \\
\hline $\begin{array}{l}\text { La táctica de "no } \\
\text { estaba disponible" }\end{array}$ & $\begin{array}{l}\text { Señalar que alguien no pudo dar su versión sobre los hechos sin esforzarse por } \\
\text { contactarlo. }\end{array}$ \\
\hline
\end{tabular}

Fuente: Merrill, Lee y Friedlander (cf. 1992: 81-83).

Brajnovic (1978: 335) explica que la propagandización del periodista puede ser un proceso casi natural:

"Los periodistas que se encuentran personalmente en la fase primitiva de adquisición de alguna necesidad empiezan a veces a servir una ideología. Primero destacando sólo aquellas noticias que apoyan su postura ideológica y silenciando las otras que podrían desmentir tal postura. Luego someten a críticas y ataque a las personas e instituciones que no piensan y actúan como ellos. Y finalmente terminan por comportarse como profesionales de la propaganda dividiendo el mundo, sus situaciones y acontecimientos, en dos polos: uno pequeño en el que se cantan ditirambos, odas e himnos, y otro más grande y diverso al que anatemizan y consideran de antemano como algo negativo y condenado a desaparecer. Esta es la propaganda espontánea que se encuentra en los medios informativos considerados imparciales y que desemboca en el dogmatismo, la intolerancia y la estrechez de horizontes, características todas ellas de un periodismo poco consciente de la libertad de expresión y de la verdad informativa".

En contraposición, Roiz (1994: 25) arguye que “aunque se encuentran elementos técnicos de persuasión en la opinión periodística, como pueden ser: la selección de opuestos, la simplificación o la apelación a la emotividad, su grado de búsqueda de la eficacia persuasiva es siempre menor que el que se encuentra en la propaganda propiamente dicha o en la publicidad".

La tercera forma de entender la relación prensa-propaganda es analizando cómo el marketing político ${ }^{15}$ (o electoral, si estamos en tiempo de comicios) busca influir en los contenidos de los medios. De plano se debe señalar que en el planeamiento del marketing electoral los medios son vistos como meros instrumentos de publicidad y propaganda. Así, Fernández y Hernández (2000: 50) señalan que “durante una campaña se emplean

15. Qualter ( $c f .1994: 180$ y ss.) entiende el marketing político como la forma de hacer política con técnicas publicitarias. En tanto las campañas políticas implican una transacción de conductas (un voto a cambio de un buen gobierno, por ejemplo), el marketing es aplicable a ellas. De este modo, los políticos se consideran "productos" que deben ajustar sus discursos (ofertas) a las emociones del ciudadano (demandas). 
los medios de comunicación para dos fines: a) Publicidad (inserciones pagadas) y $b$ ) Propaganda (apariciones en los medios, provocación de difusión de información en espacios no pagados)".

¿Provocación de difusión de información en espacios no pagados? Fernández y Hernández ( $c f$. 2000: 54-55) proponen dos formas de propagandización del periodismo: a) un acercamiento extraprofesional con los periodistas; y b) una mezcla deliberada de propaganda e información. Sobre el primer punto los autores afirman que "el éxito de una buena propaganda, la cual se mide por la cantidad favorable de notas, entrevistas, referencias, etc., en los medios, depende en gran medida del cabildeo con los periodistas, jefes de información y propietarios de los mismos [...] Como es evidente, es necesario tener una lista completa de periodistas con nombre, fotografía, historial, tendencias ideológicas, perfil, gustos, aficiones y toda clase de información para planear una estrategia de acercamiento personalizada con el candidato [...] A veces puede ser necesario contactar uno o varios periodistas experimentados que logren espacios positivos y sin costo en los medios". En el segundo punto son igual de directos, pues señalan que "se debe evitar al máximo utilizar los fondos de la publicidad y, cuando sea necesario hacerlo, las inserciones se deben elaborar de tal forma que no se observen como algo pagado, sino como parte de la información del mismo medio".

Arceo y otros (1993: 19-20) continúan en la misma línea el sostener que en una campaña "las acciones no siempre se presentan con apariencia persuasiva, al menos para el público en general, de modo que toman formas informativas, formativas, distractoras $u$ otras resultado de estas categorías". En ese sentido, recomiendan elaborar "artículos, reportajes y crónicas de periodistas aparentemente independientes en prensa, radio y televisión". ¿Aparentemente independientes?

Así, el marketing político se presenta como una forma reeditada, "blanqueada", de propaganda. Herrero (1996: 61) recuerda que es crucial distinguir propaganda y periodismo porque "algo que puede ser consustancial a la lucha política para conseguir unos fines concretos (votos, simpatizantes con una causa, movilizaciones, etc.) no se comprende en el discurso periodístico, que otros fines y una función social que cumplir [...] El engaño no figura entre los recursos que el periodismo debe utilizar para cumplir su función de información y de opinión; su función de verdad".

\section{Conclusión}

La propaganda está presente tanto en los regímenes autoritarios como en las democracias. En el primer tipo de gobierno, se expresa a través de la censura; y en el segundo, de la presión de los agentes de prensa. Los periódicos, en tanto actores políticos, son proclives a la propaganda. El periodismo puede usar (de forma más o menos soterrada) las técnicas de propaganda de los actores políticos; por ejemplo, la creación de estereotipos, la "objetividad selectiva", el uso de una "autoridad vaga", informar a través de otras fuentes y presentar opiniones como hechos. 
En la actualidad, la propaganda se presenta bajo la forma del marketing político, que busca influir en los periodistas de cualquier modo. Durante las elecciones, los agentes de prensa de los candidatos trazan estrategias para aliarse con los periodistas y neutralizar eventuales contracampañas. De esta manera, reducen el rol de la prensa a ser un elemento más de sus estrategias $^{16}$.

\section{Fuentes consultadas}

Aguilera, O. (1991). Las ideologías en el periodismo. Madrid: Paraninfo.

Arceo, J. y otros (1993). Campañas electorales y publicidad política en España (19761991). Barcelona: Escuela Superior de Relaciones Públicas.

Borrat, H. (1989). El periódico, actor político. Barcelona: Gustavo Gili.

Brajnovic, L. (1978). Deontología periodística. Zaragoza: Ediciones Universidad de Navarra.

Campbell, J. (2004). Técnicas de persuasión. De la propaganda al lavado de cerebro. Madrid: Alianza Editorial.

Chomsky, N. (2002). "El control de los medios de comunicación”, pp. 7-53. En Chomsky, N. y Ramonet, I. Cómo nos venden la moto. Barcelona: Icaria.

Chomsky, N. y Herman, E. (2001). Los guardianes de la libertad. Barcelona: Crítica.

Conejeros, S. (2000). "Periodismo y política: una relación difícil y vital”, pp. 227-236. En Cacua, A. y Priess F. (ed.). Ética y responsabilidad. Reflexiones para periodistas. Bogotá: Fundación Konrad Adenauer.

Domenach, J. (1993). La propaganda política. Buenos Aires: Eudeba.

Doob, L. (1972). “La naturaleza de la propaganda”, pp. 414-432. En Steinberg, C. (comp.). Los medios de comunicación social. México D. F.: Roble.

Durandin, G. (1983). La mentira en la propaganda política y en la publicidad. Barcelona: Paidós.

Fernández Bogado, B. (2000). "Politización de medios y periodistas", pp. 221-226. En Cacua, A. y Priess F. (ed.). Ética y responsabilidad. Reflexiones para periodistas. Bogotá: Fundación Konrad Adenauer.

16. Algunos manuales de marketing electoral, por ejemplo, recomiendan hacer pasar como información independiente avisos publicitarios pagados. 
Fernández Collado, C. y Hernández Sampieri, R. (2000). Marketing electoral e imagen de gobierno en funciones. México, D. F.: McGraw-Hill.

Gargurevich, J. (1991). Historia de la prensa peruana (1594-1990). Lima: La Voz.

Habermas, J. (1997). Historia y crítica de la opinión pública. Barcelona: Gustavo Gili.

Herrero Aguado, C. (1996). Periodismo político y persuasión. Madrid: Actas.

Kapuscinski, R. (2003). Los cinco sentidos del periodista (estar, ver, oir, compartir, pensar). México D. F.: Fondo de Cultura Económica.

Martínez Albertos, J. (2007). Curso general de redacción periodística. México D. F.: Thomson.

Merrill, J.; Lee, J. y Jay, E. (1992). Medios de comunicación social. Madrid: Fundación Germán Sánchez.

Muraro, H. (1998). Politicos, periodistas y ciudadanos. Buenos Aires: Fondo de Cultura Económica.

Oficina Nacional de Procesos Electorales (2006). Manual para periodistas. Lima: ONPE.

Parra, C. (1989). La propaganda. Lima: Ama Llula.

Peirano, L. y otros (1978). Prensa: apertura y límites. Lima: Desco.

Qualter, T. (1994). Publicidad y democracia en la sociedad de masas. Barcelona: Paidós.

Ramonet, I. (1998). La tiranía de la comunicación. Madrid: Debate.

Reardon, K. (1991). La persuasión en la comunicación. Barcelona: Paidós.

Roiz, M. (1994). Técnicas modernas de persuasión. Madrid: Eudema.

Sohr, R. (1998). Historia y poder de la prensa. Santiago de Chile: Andrés Bello.

Uceda, R. (2011, marzo 22). Papel de los medios en los trabajos de la memoria referida al conflicto armado interno peruano 1980-2000. Intervención durante del coloquio "Medios, memoria y violencia” de la Universidad Antonio Ruiz de Montoya. Lima.

Verbitsky, H. (1997). Un mundo sin periodistas. Buenos Aires: Planeta.

Young, K. (1986). “La propaganda”, pp. 195-236. En Young, K. y otros. La opinión pública y la propaganda. México D. F.: Paidós. 